\title{
The experience and management of neck pain in general practice: the patients' perspective
}

\author{
Martin Scherer • Helene Schaefer • Eva Blozik • \\ Jean-François Chenot $\cdot$ Wolfgang Himmel
}

Received: 22 January 2009/Revised: 5 January 2010/ Accepted: 16 January 2010/Published online: 12 February 2010

(C) The Author(s) 2010. This article is published with open access at Springerlink.com

\begin{abstract}
The objective of this study is to investigate the perspective and expectation of patients presenting with neck pain in general practice. The study design is a qualitative analysis of patient interviews and was conducted in a primary care setting in Germany. Twenty patients aged 20-78, according to theoretical sampling were included in the study. Patients tried to cope autonomously with the situation and consulted GPs only if their self-help had failed. When patients asked for external help, they usually focused on somatic treatment options such as massage, physiotherapy or injections. Most patients reported to have experiences with somatic therapies; however, they felt that some or all of these treatments were inefficient or led only to short-time improvements. Patients often avoided psychosocial themes when talking to doctors for fear of being branded as 'neurotic'. Although neck pain is difficult to manage and a burden for patients, they have obviously found a way of both living with their pain and a pragmatic approach of talking about their symptoms with their doctor. According to the patients' statements, the interaction between doctor and patient seems to be rather distant, ensuring that both sides avoid any issues that might touch upon psychological aspects of neck pain.
\end{abstract}

Keywords General practice - Neck pain . Physician-patient relationship · Qualitative design

M. Scherer - H. Schaefer - E. Blozik - J.-F. Chenot .

W. Himmel

Department of General Practice, University of Göttingen,

Göttingen, Germany

M. Scherer $(\bowtie) \cdot$ E. Blozik

Institute of Social Medicine, University of Lübeck,

Ratzeburger Allee 160, 23538 Lübeck, Germany

e-mail: mschere@gwdg.de; martin.scherer@uk-sh.de

\section{Introduction}

Neck pain is one of the most frequently reported complaints of the musculoskeletal system [4]. In the general population, up to $30-50 \%$ of adults experience neck pain at least once per year [13]. GPs are often consulted first for neck pain and are also responsible for long-term treatment. The management of neck pain is challenging because of a lack of effective therapies [4]. Recent Cochrane reviews investigated the effects of therapeutic interventions of neck pain such as exercise, [17] manipulation and mobilisation, [10] acupuncture, [27] and medicinal and injection therapies [21] and concluded that there is too little evidence to recommend for or against these somatic therapies. However, the Bone and Joint Decade 2000-2010 Task Force on Neck Pain and Its Associated Disorders recently recommended these interventions, [11] and they are widely used in primary care.

A large body of evidence investigated determinants, risk factors, and prognostic factors of neck pain [4, 5, 8, 14]. Non-modifiable risk factors (e.g. age, gender, genetics) and modifiable risk factors (e.g. psychosocial characteristics, smoking) have been identified. Especially the prominent role of psychosocial determinants such as social support, psychological health, or coping strategies for the course and prognosis of neck pain has been established. Albeit, this knowledge has not yet flowed into the management of patients with common neck pain [11].

However, the focus on somatic therapies might lead to medicalisation which carries the dangers of unnecessary labelling, iatrogenic illness and economic waste. Key mechanisms of medicalisation are patients' fears about the condition or disease as well as drawing attention on somatically based therapeutic options and possibly 
disregard of any psychosocial causes behind the musculoskeletal pain.

Given the unclear benefit of the existing neck pain therapies and given the inadequate consideration of psychosocial patient characteristics in the clinical neck pain management, exploring the patients' perspective may help doctors to build a confident patient relationship and allow better planning of therapeutic strategies as well as lifestyle changes. Further knowledge of patients' attitudes and experiences seems to be especially important in those instances, such as neck pain, where somatic symptoms and their psychological perception are strongly intermingled. A better knowledge of the patient perspective could also ultimately lead to more efficient health care policies.

In contrast, there is very little research regarding the patient perspective, especially how patients experience their neck pain, what expectations they bring to the doctor's office and what they think of the different therapies for their symptoms. To our knowledge, no qualitative study investigated neck pain patients' perspective in a general practice setting. We therefore conducted a qualitative study of patients who visited their GP with neck pain to better understand their attitudes and experiences regarding their illness and the treatment options administered.

\section{Methods}

\section{Study context}

This study presented here is part of a larger activity researching neck pain consisting of a qualitative and a quantitative component. It included patients, from a primary care setting in Germany, consulting at least once for neck pain between March 2005 and April 2006. Baseline characteristics and results of the quantitative sample are reported elsewhere [26]. In the qualitative part of the study, semi-structured telephone interviews were conducted in two phases of ten interviews each during the period of January 2007 to August 2007. Both parts of the study were independent from each other; i.e. the qualitative data should not validate, or triangulate, the quantitative results of the study. The study was approved by the research ethics committee of the University of Göttingen Medical Center, Göttingen, Germany (no. 17/1105).

Patient recruitment and data collection

The quantitative sample comprised of 448 patients from 15 general practices located within a radius of $30 \mathrm{~km}$ (about 20 miles) around Göttingen. Out of this sample, two separate patient groups of ten participants each were chosen to participate in semi-structured telephone interviews as follows:

(1) initially a random sample of ten patients was selected

(2) a subsequent sample of ten people was assembled according to the principles of theoretical sampling. In theoretical sampling participants are not chosen randomly but in a way that the researcher can compare relevant criteria of the previous sample to the new cases in order to support the development of distinctive categories [20].

Patients were included if they were able to speak German but had had no previous cervical spine injuries, were not suffering from cancer, not in need of nursing care and were not severely cognitively impaired. Socio-demographic and clinical information was collected in the context of quantitative analyses using a multidimensional approach. Details on quantitative data collection are reported elsewhere [26].

Interviews were conducted by a trained interviewer (H.S.), and recorded and transcribed according to standardised procedures. After the first ten interviews, the interviewees' answers were categorised in a preliminary analysis and then further participants were added to the study according to theoretical sampling principles, namely maximum and minimum variation. Maximum variation means to select participants that differ from the individuals already interviewed, whereas minimum variation means to choose similar people [19]. Determining factors were sex, age and subjective aetiology of their pain stated in the quantitative study mentioned above. A constant comparison of the new interviews to the categories was conducted which means that the labels were compared to the new data and revised if they did not fit the information the data revealed to ensure that no conclusions were drawn that were not grounded in the data [3, 18]. The process showed that data saturation had been reached after a total of 20 interviews, which meant that no more new information could be found in the interviews that explained the categories further or better, added new categories or led to the revision of categories [18].

\section{The interview guide}

We decided for semi-structured single interviews on the phone. The interviews were conducted separately as we did not want to explore shared experiences but individual [22]. The interview guide contained open-ended questions so that we could make sure that certain topics would be covered, but additionally, the participants were able to add individual further aspects. The order of questions was adapted contentwise to the thematic flow of the interviews. The interview questions had to fulfil two additional criteria: 
first, not to be led by any hypotheses and second, to be easy to understand in everyday speech and by no means suggestive. Two pilot interviews were conducted in order to validate the interview questions with respect to these criteria. Based on these preliminary interviews, some questions were reworded. The interview guide covered eight main issues (Table 1) that had been collated from an extensive literature search of qualitative studies in musculoskeletal patients. In the first question patients were asked how they describe the nature of their pain. This description was then used throughout the interview in order to make it easier and less artificial for the interview partners to talk about the neck pain. The telephone interview lasted, on average, 42 (range 19-65) min.

Analysis

Methodologically, analysis was based on Grounded Theory using a thematic framework approach. This is a method to "classify and organise data according to key themes, concepts and emergent categories" [24]. Our framework analysis comprised three steps:

(1) Labelling of patient statements On reading through the transcripts, thematic aspects were detected and labelled descriptively [24]. According to the concept of "coding up", all labels were developed from the text applying constant comparison method [2]. An index of 32 comprehensive labels emerged with which the interviews were labelled cross-sectionally. This created thematic text collections called chunks [15]. Each chunk consisted of all interview segments classified with the specific label, i.e. dealing with a particular thematic aspect. Atlas.ti was used to support the labelling process [1].

(2) Categorisation The text collections of every chunk were labelled similarly to the interview transcripts in step (1), thus developing a separate index for each.
By this, the main facets of the participants' statements referring to a thematic aspect were worked out systematically. Afterwards, these sub-labels were condensed into categories (Fig. 1). One sociologist (H.S.) prepared the categorizations and discussed them with the other members of the interdisciplinary research team (1 further sociologist, 2 GPs) in order to countercheck them.

(3) Finding themes Based on the categorizations and on reconsidering the interview transcripts, H.S. worked out connections between the 32 main labels. These broader connections were called themes. The research team checked these suggestions using constant comparison method. Figure 2 depicts the whole process of analysis.

\section{Results}

The majority of the 20 interviewees were female $(n=14)$. The first sample was randomly drawn (9 women and 1

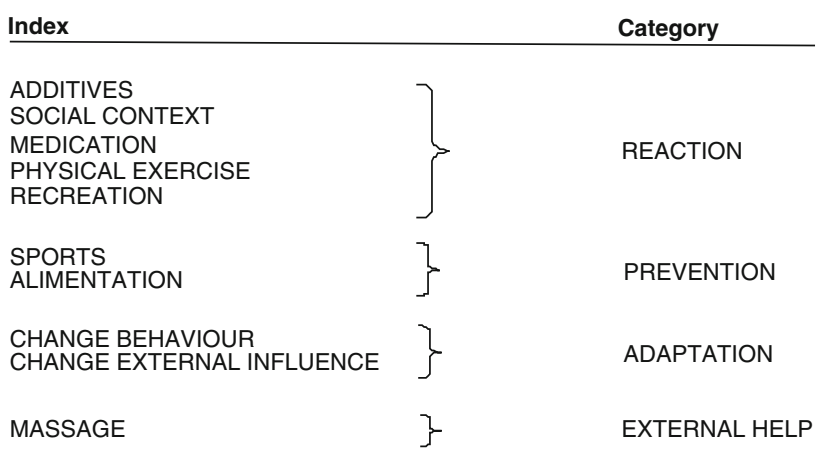

On the left the separate index for the main label "self-management". On the right the condensation into categories.

Fig. 1 Categorisation within chunks for the main label "selfmanagement"-Analysis step (2)

Table 1 Main issues covered in the interview guide

\begin{tabular}{ll}
\hline Issue & Example of question \\
\hline $\begin{array}{l}\text { Experience of pain } \\
\text { Lay aetiology }\end{array}$ & And how would you describe your (patient term)? What kind of pain is it? \\
$\begin{array}{l}\text { Role of the family } \\
\text { Future course of the disease }\end{array}$ & Has your family had an influence on your (patient term)? \\
$\begin{array}{l}\text { Management of pain (coping) } \\
\text { Doctor-patient interaction }\end{array}$ & What do you do if the pain gets very bad? \\
$\begin{array}{l}\text { Possible worries and need for } \\
\text { information }\end{array}$ & When you explain your symptoms to your doctor in detail, do you get the feeling he understands you? \\
Ideas for improved care & What questions do you worry about with respect to your (patient term)? \\
\hline
\end{tabular}

On the left the main thematic fields covered by the interview guide. Every thematic field contained 1-9 questions. In each case one of them is shown on the right 
Fig. 2 Steps of analysis

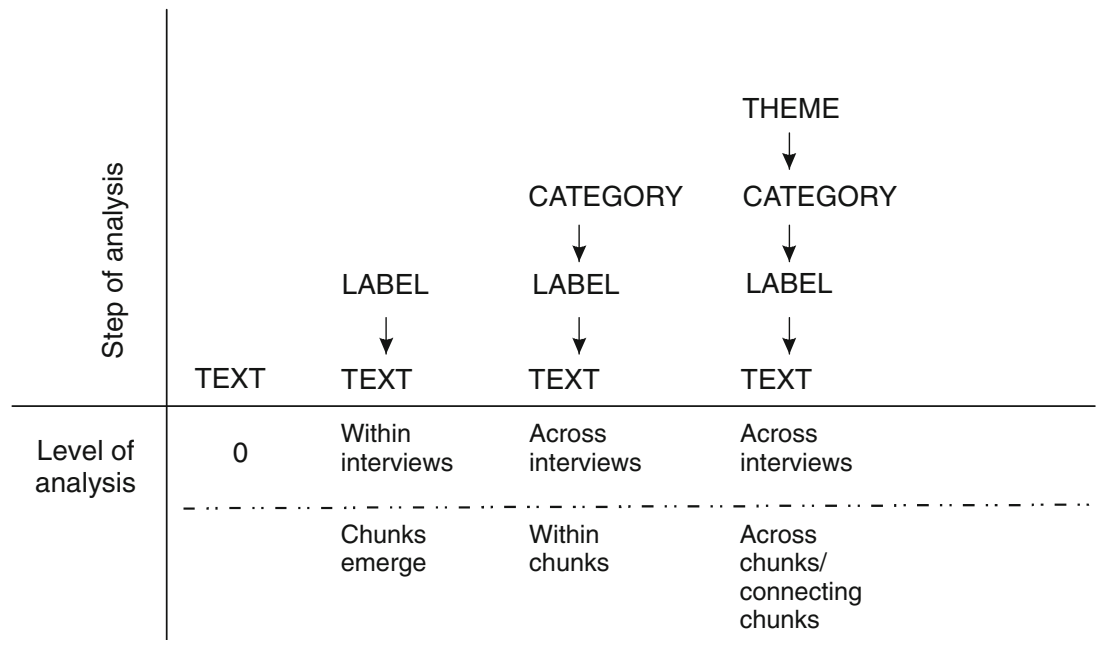

man). Unlike the women who felt that their families represented an additional burden, the single man in this group suffering from neck pain received sympathy and found family life relaxing. Therefore, we made sure that the second sample was equally distributed between the sexes ( 5 men and 5 women). In contrast to our initial hypothesis from the first series of interviews, a distinct gender effect in the experience and communication of neck pain was not detected.

Altogether, the mean age of the interviewees was 48 (range 20-78). Eighty-four percent of them (16/19) reported that they were more than 10 years at school; $30 \%$ $(6 / 14)$ were unemployed or retired, and the majority $(17 / 20,85 \%)$ lived with a partner. One person had a previous operative intervention and eight participants had a previous traumatic injury of the cervical spine. Twenty-five percent $(5 / 20)$ reported that they suffered from constant neck pain in the year preceding our study.

Overall, four major themes emerged during the process of labelling the interviews: (1) communication of patient and GP about the reason for encounter, (2) patient's competences, (3) doctor-patient situation from the patients' perspective, and (4) experiences with therapeutic options.

Communication of patients and GPs about the reason for encounter

All interviewees were familiar with the term "neck pain" and most patients used it regularly to describe their complaints. However, most preferred to additionally describe the pain in detail, specifying the affected region or naming co-symptoms; and they reported to do so when talking with their families and friends. However, some patients did not use any medical terminology but referred to their pain in concrete or metaphoric terms such as "stiff neck" or "cannot turn my head" even when consulting their GP or a specialist.
Well, as I just said, it was more like the lower back was worse, and when the upper region was also affected, I had more of an impression that it was around the shoulders and then I also mentioned the shoulder pain and not the neck pain so much. (ID 0069, 47-year-old female).

No, I would also say neck pain! OK, very well, let's say... erm, erm, yes, neck. Yes I've still got a stiff neck, but I know that my spine is, erm, very very straight. I've been to an orthopaedic specialist, and he said that, erm-very often, I'll say 'I've got a stiff neck again today' that's for sure...' a stiff neck again today' as you say... (ID 0198, 61-year-old female).

\section{Patients' competences}

Many participants preferred self-care measures for the management of neck pain and they sought professional help only when those measures failed. Self-care measures included taking analgesics, exercising, relaxation techniques or heat packs, warm showers, or electrical stimulation. Many patients felt that these measures were useful for controlling neck pain, although some patients reported concerns, e.g. about toxic, addictive or gastric side effects of analgesics. The majority of interviewees named exercising to be an effective measure to prevent neck pain. In contrast, some admitted to not exercise sufficiently or not perform any physical activities at all despite believing in their beneficial effect.

Yes, you just don't do enough back exercise. You do some exercise, but not absolutely everything that you're supposed to do for the back. (ID 0129, 38year-old male).

And, one does not do enough sports to relieve the muscles for the neck pain, you know.

H.S.: Are you doing any sports? 
No, unfortunately not.

H.S.: Why not?

Erm, partly due to laziness, to be honest. Partly due to, sometimes due to lack of time. (ID 0007, 42-yearold female).

However, few participants were not convinced that they would benefit from exercising.

And even if I had started exercising, I assume it wouldn't have gone from one day to the next, would it? Rather, I'd expect that I would have had massive muscle ache. (ID 0006, 44-year-old female).

Another way for the individuals of handling neck pain was to change their behaviour or modify the environment that provokes the pain. For example, persons avoid turning the head, knitting, carrying heavy weights, or driving a car. Two interviewees reported that they discussed their neck problems with their employers and were subsequently allowed to modify their work environment, e.g. by changing work. In contrast, two patients did not avoid tasks that aggravated their pain. One person was not able to introduce any change in the work environment that was supposed to provoke neck pain; the other person was not willing to limit gardening due to neck pain.

Doctor-patient situation from the patients' perspective

Generally, persons visit a doctor when self-care measures become ineffective. This is the case, e.g. if a person develops significant impairment in motion or if pain intensity increases considerably. However, the interviewees mentioned several obstacles for doctor visits such as long waiting times or disagreement with the treatments suggested by their GP.

Erm. Well, I think, I suppose, I've lived with it already for so long. There's always something else that I can do that occurs to me that'll make it better ... Then I don't have to constantly be bothered about going somewhere or other to the doctor. I just haven't got time for that-time's simply too valuable to... somehow, living with my kid ... to be sitting around in a waiting room. (ID 0181, 27-year-old female).

H.S.: But you do not visit a doctor in such a situation? No, because,-I, I know what happens then. Then, yes, ok, erm. Medication and physiotherapy [...]. How did he say? Yes, I don't always understand what people think. They can be healthy without pills until 80 an so on. Yes, because I said, I really don't want (laugh) to take still such heavy pills and I am not yet 80. I am 60 for now (laugh) in quotation, yes, but, erm, that's how they are, these general practitioners, so, the orthopedists. I think so, yes. (ID 0198, 61-yearold female).

Although self-help was important, many patients requested external help, such as massage, physiotherapy, or injections of local anaesthetics, when their self-management measures were no longer effective. As these medical treatment options are usually performed or have to be prescribed by doctors, patients visited their doctors with the predefined aim of receiving these therapies. Most patients wanted to have their self-diagnosed treatment needs fulfilled and seemed to be less interested in professional medical counsel. Insofar, consulting the doctor or visiting the practice may be considered as an extension of self-care initiatives.

And when I realise that the intervals between these attacks are getting shorter and shorter, then I'll go to the doctor and get him to prescribe some massage. And when, erm, that's been going for a while, then (the neck pain) it's OK for a time and I don't have as much trouble. And then at some point it'll come again. (ID 0181, 27-year-old female).

Ah, I don't know. At the moment, I try using the tablets and my own methods to keep things going reasonably well and when that really doesn't help, I fetch my injections (ID 0488, 46-year-old female).

Only few patients were aware of a concrete diagnosis concerning their neck pain problems and particularised "fibromyalgia", "skoliosis", or "prolapsed intervertebral discs". Most patients did not seem to be much interested in a specific diagnosis or aetiology of their symptoms; some did not remember ever receiving a diagnosis from their GP and others had received only a vague diagnosis. However, most patients were not dissatisfied with not knowing a concrete diagnosis as they primarily focused on pain relief and success of the therapies suggested.

That means that it's really tense and I don't know that it's really not a slipped disc or something. After all, in the end, it's not so important, as you're just happy when.... (ID 0148, 45-year-old female).

Well, OK, I still haven't actually asked that exactly. I personally just say to myself that it's just part of getting old. It's a result of my history, urm, that this misalignment-developed-yeah, they told me, it's because of this mis, erm, alignment of the spine - that causes these pains. Bam-that's it! (ID 0198, 61-yearold female).

Many respondents did not like talking about their pain either with their GP or their family and friends. When we asked patients whether they believed the doctor understood their suffering, a typical answer was, "I believe they do 
understand me...I don't think so much about that" (ID 0223). Obviously, both parties did not go into any detail. This may be motivated by the feeling that a more extensive talk about pain might provoke a psychological hypothesis such that patients are afraid to be stigmatised or branded neurotic:

Yes, I have thought about that a couple of times. But it's difficult to decide for yourself if it's because of that or not. And if you mention that to a doctor then they'll think its something psychological, won't they? (ID 0006, 44-year-old female).

\section{Experiences with therapeutic options}

Most patients had experiences with several neck pain therapies, especially physiotherapy, massage, injections, and acupuncture. In almost all interviews, patients reported that they expected to receive such therapies.

I had sort of thought that I'd be prescribed some physiotherapy or maybe a mudpack or something. Naturally something that'll bring the quickest relief. (ID 0006, 44-year-old female).

Repeatedly, interviewees considered health system regulations to be a major factor that hampers their doctors prescribing them physiotherapy or massage.

No. There were only problems that they are not allowed to prescribe so much massage and, or physiotherapy. (ID 0129, 38-year-old male).

At the same time, patients complained about the inefficacy of some or all of these therapies and seemed to be disappointed with their doctors for being unable to prescribe anything better.

Yes. Well, along the lines of: Do some exercise and go swimming, then you'll not have any back problems. Like that, except that sometimes it's said a bit differently. And that of course was naturally pretty useless at that point in time. (ID 0006, 44-year-old female).

Yes, they (the doctors) do say that it comes from the neck, and I have, erm, already had some physiotherapy for that. But, well, nothing else gets done. (ID 0236, 34-year-old female).

Its no use. Well... I'll get some some massage done again.

H.S.: Even though you think it doesn't help?

Patient: Well, it does do something for a while, but it doesn't actually achieve anything, no (ID 0223, 76-year-old female).

...well I was already at the neurologist (short pause) and all he prescribed was massage and injections. (ID 0459, 78-year-old female).
Several patients seemed to confuse the terms "massage" and "physiotherapy" or used both terms equivalently. Massage, especially seemed to have a high emotional relevance or significance for patients.

H.S.: Have you had massages?

Patient: I had loads of physiotherapy, yes. (ID 0488, 46-year-old female).

H.S.: Yes. And why do you think the physiotherapy didn't help?

Patient: Well, I can't say I've no idea. (laugh). Maybe I didn't go along with it properly or something. Maybe I was a bit too lazy. I just didn't get the feeling that it was achieving much. Somehow with massage there's more there... (ID 0082, 48-year-old female).

The reason for this may be that many patients received massage from a physiotherapist, and some reported that they were massaged instead of being instructed on specific physiotherapeutic exercises.

Patients' attitudes regarding the effectiveness of massage were mixed. For example, five interview partners regarded massage as a "first aid" treatment for acute pain or as the preparation of further treatment options. However, four patients felt that massage was helpful only for temporary relief and did not really contribute to improvement of their neck problems. For the most part, massage was seen as a helpful treatment option, although patients found it difficult to schedule it into their everyday life.

Yeah. So, what really helps, but what I unfortunately don't ever have time for, is massage and stuff. Yeah, massage is really great. (ID 0082, 48-year-old female).

Attitudes towards injection therapies were also diverse. Some patients appeared to be frustrated because injections took only short-time effects and did not act causally. Two interviewees were disappointed to have received injection therapies from a specialist, because they expected to receive another therapeutic intervention as they had already obtained from their GP. Some patients felt that administering an injection was a sign that their doctor was not willing to handle the neck problems of his patient in-depth. There were also contrasting opinions. For example, one patient who had asked his doctor for an injection felt that he was taken seriously when he received this therapy. Others rated injections to be helpful measures. However, the meaning of injections for the patients seems also to be linked with the doctor-patient relationship. For example, one patient was very satisfied with injection therapy administered by her GP. When receiving injections from other doctors she felt that they "gave her short shrift", as 
this intervention has not been embedded in a comprehensive doctor-patient dialogue.

H.S.: And what did the other GPs say where this comes from?

They didn't say anything, they only gave injections therein, and that was it. (ID 0488, 46-year-old female).

\section{Discussion}

In this qualitative study, 20 patients reported their experiences of neck pain in a primary care setting. They mainly tried to cope autonomously with the situation and they consulted a GP only if their self-help had failed. When patients asked for external help, they usually focused on concrete treatment options such as massage, physiotherapy or injections. Patients seemed to mainly expect that doctors fulfil their self-diagnosed treatment needs and were less interested in medical advice. Expectations and experiences with treatment options such as physiotherapy, massage, or injections were very diverse. Additionally, the doctorpatient relationship seems to influence the way patients perceive the effects of therapies.

Our results allow a richer exploration of the details of patient accounts and the appreciation of both frequent and rare experiences. With regard to the doctor-patient relationship, we should consider that our interview partners only express their attitudes and talk about their perception. Neither had their doctors the chance to complete these accounts from their perspective nor could we get a more balanced view from direct observations of the interaction.

To the best of our knowledge, this is the first qualitative study of primary care patients with neck pain. Previous qualitative studies have focused on patients with chronic back problems where the credibility of their pain is a major issue. Drawing on data from a Norwegian online discussion list and from in-depth interviews with Norwegian back pain sufferers, Glenton [9] described a patient fear that the reality of their pain was under question. Werner and Malterud [28] reported that women with unexplained chronic pain had negative experiences during medical encounters which included lack of understanding, feeling rejected, ignored, being belittled or indeed blamed for their condition. Interestingly, such feelings and experiences did not seem to be a major issue for neck pain sufferers in our study. One reason for the small number of negative experiences reported here may be due to the fact that unspecific neck pain is usually managed autonomously and resolves within days; it becomes chronic in only $10 \%$ of neck pain patients [6].
Patients in our study seemed not particularly interested in the concrete aetiology of their neck pain problems, especially when they felt that they were not able to modify these reasons. Generally, patients seemed to avoid psychosocial themes when talking to doctors, probably due to the fear of being branded 'neurotic'. Indeed, a large body of evidence shows that patient characteristics such as psychosocial factors are determinants, risk factors and prognostic factors of neck pain [4]. Some authors have discussed whether the unwillingness to accept psychosocial causes of illness resides with the patient or the doctor [7, 23]. Although we only interviewed patients, our results suggest that both, patients and doctors alike, refrain from raising the issue of psychosocial problems; a discussion related to this could be time consuming (for the doctor) or uncomfortable (for the patient). In this way, unwanted topics can be avoided and the typical ritual of requesting and prescribing somatic treatment options thereby maintained.

Doctors could overcome such barriers to talk about psychosocial issues by adopting the patients' own terms when talking about neck pain. Patients prefer concrete or metaphoric terms such as "stiff neck" to the term "neck pain" when referring to their ailment. Doctors might use these individual descriptions as a way to build a relationship with the patient and to develop a better understanding of the patient's feelings and experiences. Using patient's own vocabulary could also represent the key to initiate a conversation regarding possible psychosocial causes and consequences of neck pain. However, before we can recommend that doctors address psychosocial topics, we should be sure that psychosocial intervention might have a positive effect on, for example, the level of disability and duration associated with the neck pain. For patients with low back pain, randomised controlled trials have already been conducted. Their results, however, showed only small differences between psychosocial intervention and active control treatments in improvement in function or other outcome measures $[12,16]$. Therefore, it may be prudent to await evidence for effective strategies to address those issues in patients with neck pain.

With the modern, non-paternalistic doctor-patient relationship, the autonomous and self-confident patient is considered an equal partner with the doctor [25]. Patients in our study showed, or at least mentioned, that they had taken steps to self-manage their condition. However, this did not necessarily represent active coping such as taking preventive measures or exercise. Rather, patients in our study frequently had very concrete ideas of which therapies would help them, and most frequently, these therapies were passive such as massage and/or injections as opposed to active interventions such as lifestyle modifications. As the requested interventions usually need a prescription, 
patients were sensible of the fact that their doctor allows or denies access to such therapies. Obviously, the passive therapeutic options have a high emotional value for most interview partners but their effectiveness was also questioned. However, most of the patients were very aware of the inefficacy or limited value of some or all of these therapies. Such ambivalence is also apparent in the most recent recommendations from the literature $[10,17,21$, 27]. Exercise, manipulation and mobilisation, acupuncture, and medicinal and injection therapies are widely used in primary care, although there is too little evidence supporting the use of these therapies. This might result in medicalisation, economic waste, and even adverse events $[17,21]$.

\section{Conclusions}

Although neck pain is difficult to manage and a burden for patients, they have obviously found both a way of living with their pain and a pragmatic approach for visits with their doctor. According to the patients' statements, the interaction between doctor and patient in many cases does not seem to be warm but is rather distant, ensuring that both sides avoid any issues that might touch upon psychological aspects of neck pain. Avoiding these issues may be justified as effective therapies are lacking and it is unknown if a psychosocial intervention would have any beneficial effects for the patient. However, suppressing psychosocial issues when they might be relevant for aetiology, course, and prognosis of neck pain may bring about the prescription of ineffective therapies, often supporting the patients' passivity, and possibly leading to a degree of medicalisation. Future research emanating from these results about patients' perspectives should investigate attitudes and experiences of all stakeholders involved in the care of neck pain patients. By combining these perspectives it may be possible to denominate communicative expectancies of all sides and of problems encountered in the treatment of neck pain.

This study has implications for clinical practice. When prescribing therapeutic measures such as physiotherapy or massage, doctors should be aware that patients, at least partly, visit them with the aim of receiving such a prescription. But patients are also sceptical with respect to the efficacy and to potential adverse events. Most patients gave the impression of feeling competent in their ailment and in its management. However, doctors should keep in mind that patients cannot foresee other potential consequences of therapies such as iatrogeneous chronification or medicalisation. It may be inconvenient for doctors to refuse such requests, and, thus, to protect their patients from adverse and negative outcomes.
Acknowledgments The study was supported by the German Ministry of Education an Research (BMBF), Grant No. 01 GK 0516. The primary investigator was funded by a Young Investigators' Award of the BMBF. We gratefully acknowledge Laila Burla, Swiss Health Observatory, Neuchâtel, for helpful comments on the interview guide.

Conflict of interest statement Martin Scherer is head of the guideline development commitee of the German College of General Practitioners and Family Physicians (DEGAM) and principal author of the DEGAM-Guideline Nr. 13 ("Neck pain").

Open Access This article is distributed under the terms of the Creative Commons Attribution Noncommercial License which permits any noncommercial use, distribution, and reproduction in any medium, provided the original author(s) and source are credited.

\section{References}

1. ATLAS.ti (2008) The Knowledge Workbench, Visual Qualitative Data Analysis, Version 5.0.66. ATLAS.ti Scientific Software Development, Berlin

2. Bowling A (2002) Research methods in health. Investigating health and health services. Open University Press, Buckingham, Philadelphia

3. Bryman A (2004) Social research methods. Oxford University Press, Oxford

4. Carroll LJ, Hogg-Johnson S, van der Velde G, Haldeman S, Holm LW, Carragee EJ et al (2008) Course and prognostic factors for neck pain in the general population: results of the Bone and Joint Decade 2000-2010 Task Force on Neck Pain and Its Associated Disorders. Spine 33(4 Suppl):S75-S82

5. Côté P, van der Velde G, Cassidy JD, Carroll LJ, Hogg-Johnson S, Holm LW et al (2009) The burden and determinants of neck pain in workers: results of the Bone and Joint Decade 2000-2010 Task Force on Neck Pain and Its Associated Disorders. J Manip Physiol Ther 32:S70-S86

6. Cote P, Cassidy D, Carroll L (1998) The Saskatchewan health and back pain survey: the prevalence of neck pain and related disability in Saskatchewan adults. Spine 23:1689-1698

7. Dowrick C, Gask L, Hughes JG, Charles-Jones H, Hogg JA, Peters S et al (2008) General practitioners' views on reattribution for patients with medically unexplained symptoms: a questionnaire and qualitative study. BMC Fam Pract 9:46

8. Demyttenaere K, Bruffaerts R, Lee S, Posada-Villa J, Kovess V, Angermeyer MC et al (2007) Mental disorders among persons with chronic back or neck pain: results from the World Mental Health Surveys. Pain 129:332-342

9. Glenton C (2003) Chronic back pain sufferers-striving for the sick role. Soc Sci Med 57:2243-2252

10. Gross AR, Hoving JL, Haines TA, Goldsmith CH, Kay T, Aker P et al (2004) Manipulation and mobilisation for mechanical neck disorders. Cochrane Database Syst Rev (1):CD004249

11. Guzman J, Haldeman S, Carroll LJ, Carragee EJ, Hurwitz EL, Peloso P et al (2008) Clinical practice implications of the Bone and Joint Decade 2000-2010 Task Force on Neck Pain and Its Associated Disorders: from concepts and findings to recommendations. Spine 33:199-213

12. Hay EM, Mullis R, Lewis M, Vohora K, Main CJ, Watson P et al (2005) Comparison of physical treatments versus a brief pain-management programme for back pain in primary care: a randomised clinical trial in physiotherapy practice. Lancet 365:2024-2030

13. Hogg-Johnson S, van der Velde G, Carroll LJ, Holm LW, Cassidy D, Guzman J et al (2008) The burden and determinants 
of neck pain in the general population: results of the Bone and Joint Decade 2000-2010 Task Force on Neck Pain and Its Associated Disorders. Spine 33(Suppl):S39-S51

14. Hogg-Johnson S, van der Velde G, Carroll LJ, Holm LW, Cassidy JD, Guzman J et al (2009) The burden and determinants of neck pain in the general population: results of the Bone and Joint Decade 2000-2010 Task Force on Neck Pain and Its Associated Disorders. J Manip Physiol Ther 32:S46-S60

15. Huberman AM, Miles MB (1994) Qualitative data analysis: an expanded sourcebook, 2nd edn. Library of Congress Catalogingin-Publication Data. Sage, London, pp 50-88

16. Jellema $P$, van der Windt DA, van der Horst HE, Twisk JW, Stalman WA, Bouter LM (2005) Should treatment of (sub)acute low back pain be aimed at psychosocial prognostic factors? Cluster randomised clinical trial in general practice. BMJ 331:84-88

17. Kay TM, Gross A, Goldsmith C, Santaguida PL, Hoving J, Bronfort $\mathrm{G}$ et al (2005) Exercises for mechanical neck disorders. Cochrane Database Syst Rev (3):CD004250

18. Kumar S (1999) Grounded theory. In: Gantley M, Harding G, Kumar S, Tissier J (eds) An introduction to qualitative methods for health professionals. The Royal College of General Practitioners, London, pp 17-18

19. Lamnek S (2005) Qualitative social research. Weinheim, Basel, pp 191

20. Mays N, Pope C (2000) Quality in qualitative health research. In: Pope C, Mays N (eds) Qualitative research in health care. BMJ Books, London, pp 89-101
21. Peloso P, Gross A, Haines T, Trinh K, Goldsmith $\mathrm{CH}$, Burnie S et al (2007) Medicinal and injection therapies for mechanical neck disorders. Cochrane Database Syst Rev (3):CD000319

22. Pope C, van Royen P, Baker R (2002) Qualitative methods in research on healthcare quality. Qual Saf Health Care 11: $148-152$

23. Ring A, Dowrick CF, Humphris GM, Davies J, Salmon P (2005) The somatising effect of clinical consultation: what patients and doctors say and do not say when patients present medically unexplained physical symptoms. Soc Sci Med 61:1505-1515

24. Ritchie J, Spencer L, O'Connor W (2003) Carrying out qualitative analysis. In: Ritchie J, Lewis J (eds) Qualitative research practice. A guide for social science students and researchers. Sage, London, pp 219-262

25. Rodriguez-Osorio CA, Dominguez-Cherit G (2008) Medical decision making: paternalism versus patient-centered (autonomous) care. Curr Opin Crit Care 14:708-713

26. Scherer M, Blozik E, Himmel W, Laptinskaya D, Kochen MM, Herrmann-Lingen C (2008) Psychometric properties of a German version of the neck pain and disability scale. Eur Spine J 17:922929

27. Trinh KV, Graham N, Gross AR, Goldsmith $\mathrm{CH}$, Wang E, Cameron ID et al (2006) Acupuncture for neck disorders. Cochrane Database Syst Rev (3):CD004870

28. Werner A, Malterud K (2003) It is hard work behaving as a credible patient: encounters between women with chronic pain and their doctors. Soc Sci Med 57:1409-1419 